\title{
Uma análise do Projeto de formação profissional de professores privilegiada pelo PROFMAT
}

\section{An analysis of the project of professional training privileged by PROFMAT}

\author{
Marlova Estela Caldatto ${ }^{1}$ \\ Dario Fiorentini ${ }^{2}$ \\ Regina Maria Pavanello ${ }^{3}$
}

\section{Resumo}

Este estudo visa analisar e discutir o projeto acadêmico do Programa de Mestrado Profissional em Matemática em Rede Nacional (PROFMAT), destacando, sobretudo, a natureza dos conhecimentos formativos que são priorizados por essa política pública de desenvolvimento docente. Tendo por base a teorização de Gimeno Sacristán, esse projeto foi considerado neste artigo o currículo oficial desse programa, que foi analisado a partir de uma perspectiva curricular crítica e de pesquisas que investigam o "conhecimento especializado do professor de matemática". As análises evidenciaram que esse programa de pós-graduação privilegia a disseminação de códigos e conhecimentos vinculados fortemente à prática do matemático profissional, ao mesmo tempo que não aborda conhecimentos referidos pela literatura especializada como sendo fundamentais para a prática do professor que ensina matemática na educação básica.

Palavras-chave: Currículo; Formação de Professores em Serviço; Mestrado Profissional.

\begin{abstract}
This study aims to analyze and discuss the academic project of the Professional Master's Program in Mathematics in National Network (PROFMAT), highlighting above all the nature of the formative knowledge that is disseminated (prioritized) by this public policy of teacher development. Based on the theorization of Gimeno Sacristán, this project was considered in this article the official curriculum of this program, which was analyzed from a critical curricular perspective and from researches that investigate the "specialized knowledge of the mathematics teacher". The analysis showed that this postgraduate program privileges the dissemination of codes and knowledge strongly linked to the practice of the professional mathematician while not addressing knowledge referred by the specialized literature as being fundamental to the practice of the teacher who teaches mathematics in basic education.
\end{abstract}

Keywords: Curriculum; Teacher Training in Service; Master's Degree.

\section{Submetido em: 21/11/2017 - Aceito em: 21/04/2018 - Publicado em: 13/06/2018}

1 Doutora em Educação para a Ciência e a Matemática pela Universidade Estadual de Maringá (UEM). Professora da Universidade Tecnológica Federal do Paraná, Brasil. E-mail: marlovacaldatto@utfpr.edu.br.

${ }^{2}$ Doutor em Educação pela Universidade Estadual de Campinas (UNICAMP). Docente do Programa de PósGraduação em Educação da UNICAMP. Brasil. E-mail: dariofiore @ terra.com.br.

${ }^{3}$ Doutora em Educação pela UNICAMP. Docente do Programa de Pós-Graduação em Educação para a Ciência e a Matemática da UEM. E-mail: reginapavanello@ hotmail.com. 


\section{Introdução}

A pesquisa em tela tem por objeto de estudo o Projeto Acadêmico do Programa de Mestrado Profissional em Matemática em Rede Nacional (PROFMAT). Esse programa de pós-graduação, que tem como público alvo os professores de Matemática em exercício nos anos finais do Ensino Fundamental e Ensino Médio, é coordenado pela Sociedade Brasileira de Matemática (SBM) e conta com o apoio do Instituto Nacional de Matemática Pura e Aplicada (IMPA).

O PROFMAT, de acordo com a organização das áreas do conhecimento proposta pela Coordenação de Aperfeiçoamento de Pessoal em Nível Superior (CAPES), vincula-se à área do Conhecimento Matemática. Tal vinculação é originária do processo de submissão, apreciação e aprovação, pela CAPES, de um Projeto Acadêmico. Tal documento apresenta as informações gerais de um programa de pós-graduação stricto sensu, tais como: a caracterização do curso (objetivos / perfil profissional a ser formado, diretrizes); descrição das disciplinas (grade e ementário); identificação da proposta; Áreas de Concentração/Linhas de Pesquisa; corpo docente (titulação, produção acadêmica, experiência internacional de formação, instituição em que trabalha etc.); Projetos (vinculados), entre outras.

Esse projeto é interpretado por nós como o currículo oficial (prescrito) do PROFMAT, uma vez que apresenta "uma seleção organizada dos conteúdos a aprender, os quais, por sua vez, regularão a prática didática” (Sacristán, 2013, p. 17) que ocorrerá durante o processo de instrução. Assim, esse documento expõe a instrumentalização concreta que torna esse curso de formação de professores um "sistema social" (Sacristán, 1998).

Nesse cenário, o objetivo deste artigo é discutir o currículo do PROFMAT, destacando sobretudo sua concepção de formação profissional de professores de matemática e o tipo de conhecimento privilegiado por esse programa de pós-graduação, que é parte de uma política pública de desenvolvimento docente. Assim, procuraremos caracterizar e analisar os discursos e as concepções subjacentes a esse currículo, identificando a natureza do conhecimento formativo do professor que vem sendo considerado legítimo pelas instâncias políticas brasileiras.

A cristalização desse objetivo decorre da hipótese que um estudo dessa natureza contribuirá para a reflexão e compreensão da resposta produzida pelas instâncias governamentais (por meio do PROFMAT) para uma questão fundamental e socialmente relevante: $\mathrm{O}$ que os professores de matemática precisam saber para ministrar aulas de qualidade? (Ball, Lubienski \& Mewborn, 2001). Ademais, estudos com essa natureza podem contribuir para o debate sobre as políticas de formação docente, trazendo subsídios que contribuam para a valorização dessa categoria profissional, à melhoria da qualidade da educação e da condição de exercício de cidadania das crianças, jovens e adultos em processo de formação nas redes de ensino brasileiras (Gatti, Barreto \& André, 2011).

Visando tal objetivo, o artigo inicia-se com uma breve caracterização do PROFMAT e o delineamento metodológico da pesquisa. A seguir, interpretamos o currículo como um 
instrumento de disseminação cultural e tecemos uma discussão sobre o conhecimento do professor de matemática. Por fim, apresentamos a análise do currículo do PROFMAT e algumas discussões e considerações finais.

\section{Breve caracterização do PROFMAT}

O PROFMAT é um programa de pós-graduação, voltado para a formação em serviço de professores, que tem como objetivo principal proporcionar uma

(...) formação profissional sólida em Matemática, que contemple as necessidades do trabalho cotidiano dos professores no espaço da escola, assim como suas necessidades de desenvolvimento e de valorização profissional. Visa, ainda, o desenvolvimento de uma postura crítica acerca do trabalho nas aulas de Matemática, na Educação Básica (SBM, 2017, p. 6).

Esse programa de pós-graduação, ao enfatizar a formação de docentes atuantes na Educação Básica, ainda que voltado estritamente à matemática, tornou-se um programa modelo para a instituição de uma política nacional de formação continuada de professores na modalidade de pós-graduação [mestrados profissionais em rede], haja vista o surgimento posterior de outros programas de mestrado profissional em rede, voltados ao Ensino Básico, como, por exemplo: o ProfLetras (2013); o Programa de Mestrado Nacional em Ensino de Física (MNPEF) (2013); e o ProfHistória (2014).

Ofertado na modalidade semipresencial, o PROFMAT é formado por uma rede de Instituições de Ensino Superior no contexto da Universidade Aberta do Brasil que, no ano de 2017, disponibilizou um total de 1605 vagas distribuídas em 75 Instituições de Ensino Superior (denominadas “instituições associadas”), localizadas em 27 unidades da federação. No quadriênio 2013-2016, quando foram ofertadas 10024 vagas, somente 2988 (30\% dos ingressantes) delas culminaram em egressos titulados (SBM, 2017).

Na medida em que o PROFMAT é direcionado à formação [estritamente matemática] dos docentes de Matemática que atuam na educação básica, possui amplitude nacional e foi determinante para a instituição de uma política nacional de formação continuada de professores na modalidade de pós-graduação, ele configura-se como uma ação governamental, por intermédio da CAPES, inédita que objetiva o fomento à formação de professores no Brasil. Esse ineditismo perpassa inclusive o formato de gestão e financiamento, uma vez que essa fundação financiou (e financia) todas as etapas desse programa de formação de professores, inclusive a elaboração do projeto acadêmico, conforme evidencia o fragmento abaixo:

A especificidade do Programa de Mestrado em Matemática em Rede exigiu da CAPES investimentos diferenciados. Para viabilizar esses investimentos, a CAPES firmou, a pedido da Sociedade Brasileira de Matemática, um convênio de cooperação com o Instituto de Matemática Pura e Aplicada (IMPA), por meio do qual foram repassados recursos destinados à manutenção do curso. $\mathrm{O}$ citado convênio teve como objetivo: "Concepção, Elaboração e Implantação do curso de Mestrado Profissional em Matemática em Rede Nacional" e importou inicialmente no valor de R\$ 
14.304.000,00 (quatorze milhões trezentos e quatro mil reais), sendo os recursos destinados a: concepção, elaboração e implantação do PROFMAT; obrigações tributárias e contributivas; serviços de terceiros e pessoa jurídica; material de consumo. Além disso, a CAPES concedeu bolsas de estudo para alunos do curso ${ }^{4}$ (CAPES, 2013, p. 10).

Entendemos que diante desse ineditismo, bem como do grande volume de recursos públicos canalizados à sua promoção e execução, tornam-se relevantes e necessários estudos que visem compreender a natureza do PROFMAT, bem como sua concepção, implementação e, principalmente, seus resultados.

\section{Objetivo da pesquisa e seu delineamento metodológico}

Conforme exposto anteriormente, o objetivo deste artigo é descrever e discutir o currículo do PROFMAT, destacando sobretudo sua concepção de formação profissional de professores de matemática. Assim, procuramos caracterizar os discursos adotados no decorrer desse currículo, identificando a natureza do conhecimento formativo do professor de matemática que tem sido considerado legítimo e pertinente pelas instâncias políticas brasileiras.

A discussão sobre componentes do Projeto Acadêmico do PROFMAT, entendido neste artigo como o currículo oficial do referido curso, suscita a elucidação do entendimento que a CAPES, fundação que aprovou e fomenta a implementação dessa política pública de formação de professores, sobre os itens que compõem o projeto acadêmico de um programa de pós-graduação stricto sensu. Assim, no decorrer da discussão nos baseamos no documento que balizava o processo de submissão de propostas de programa de pós-graduação no ano de 2010, ano em que ocorreu a recomendação da abertura do PROFMAT junto a tal órgão governamental (CAPES, 2010).

Além disso, para delinearmos essa discussão, fizemos duas opções de ordem metodológica. A primeira delas refere-se à adoção de teorias que subsidiam nossa discussão sobre o currículo e que o interpretam como sendo um instrumento de disseminação cultural. Embora os referenciais teóricos curriculares ofereçam instrumentos para a análise do Projeto Acadêmico do PROFMAT, há necessidade de referenciais teóricos mais específicos. No caso da presente pesquisa, optamos pela adoção de estudos que discutem a formação profissional do professor de Matemática que atua na Educação Básica (nossa segunda opção). Essas opções se configuram como uma dentre outras possibilidades que nos permitem discutir, criticar e realizar, na prática, a análise do currículo prescrito do PROFMAT, tendo em vista a formação de professores de Matemática que atuam na Educação Básica.

A adoção de teorias curriculares que interpretam esse tipo de documento oficial, como sendo um instrumento de disseminação cultural, permite-nos olhar não somente para a transmissão - pelo professor - do conhecimento (por meio das teorias tradicionais

\footnotetext{
${ }^{4}$ Somente os acadêmicos do PROFMAT que comprovarem vínculo empregatício com instituições de ensino públicas destinadas à Educação Básica são contemplados com bolsa de estudo provenientes da CAPES.
} 
curriculares) ou para os meios - objetos, materiais - utilizados para a transmissão do conhecimento (por meio de teorias tecnicistas), mas, também, para as tensões e relações de poder presentes na educação, identificando o que "determinados grupos sociais e classes, em determinadas instituições e em determinados momentos históricos, consideram conhecimento legítimo" (Apple, 2006, p. 83, grifo do autor).

Em relação à nossa segunda opção metodológica, adotamos como referencial pesquisas originárias de grupos de pesquisa e/ou pesquisadores que discutem o conhecimento especializado do professor de Matemática, destacando, especialmente, a dimensão matemática desse conhecimento (Bromme, 1993; Ball et al., 2008; Hill et al., 2008; Krauss et al., 2008; Ma, 2009; Baumert et al., 2010; Carrillo et al., 2013). Esses estudos, que possuem diferentes vertentes epistemológicas e metodológicas, foram desenvolvidos em diversos contextos. Entretanto, todos discutem e analisam a atividade do professor de Matemática no ambiente escolar e os conhecimentos necessários e fundamentais para a promoção do ensino e da aprendizagem da matemática na escola básica. Tais estudos caracterizam-se também por estabelecerem conexão entre a efetividade do ensino e a efetividade da aprendizagem da matemática escolar. Ademais, pelo menos duas dessas pesquisas são originárias de projetos vinculados aos governos norte americano (Ball et al., 2008; Hill et al., 2008) e alemão (Krauss et al., 2008; Baumert et al., 2010).

\section{O currículo como instrumento de disseminação cultural}

A reflexão sobre a política de formação docente PROFMAT, particularmente sobre seu projeto acadêmico, nos remete ao ciclo contínuo de políticas proposto por Bowe, Ball e Gold (1992), um referencial analítico de políticas educacionais composto por três contextos fundamentais: a) o contexto da influência, que é o ponto de partida para a(s) política(s), uma vez que se configura como sendo a arena de construção e legitimação dos discursos políticos que buscam delinear, em um dado momento, a educação e seus propósitos. De modo que essa arena também pode sofrer influência, por exemplo, de grupos e/ indivíduos que "vendem" suas soluções no mercado político e acadêmico por meio de periódicos, livros, conferências e "performances" de acadêmicos que viajam para vários lugares para expor suas ideias etc. (Mainardes, 2006); b) O contexto da produção de texto, que se caracteriza por originar os documentos oficiais (textos legais, textos políticos, comentários formais, etc.) que possuem uma linguagem de interesse público da sociedade e representam e balizam a política nos contextos macro e micro. Além disso, tais textos não são, essencialmente, internamente coerentes e claros, e podem até ser contraditórios e usar termos-chave de modo diverso (Mainardes, 2006); c) O contexto da prática, que é o momento em que os textos passam a ser reinterpretados e implementados. Nesse momento, os textos passam a ser contestados, mediados e diferencialmente representados por diferentes atores em diferentes contextos (Ball, 2015).

O documento curricular nesse modelo analítico é composto por um conjunto de textos, que estão mergulhados em um discurso que não é independente de história, poderes e 
interesses que se irradiam capilarmente. Sendo que tais textos, quando migram de um contexto (do ciclo) para outro, possuem seus sentidos alterados. Assim, os currículos (e ações derivadas) são classificados como essencialmente textuais, uma vez que pertencem à fase primária do processo de implementação da política.

Apple (2006) define o currículo como um ente educacional que expressa os conteúdos e códigos que ordenam um sistema de ensino, e que possui como uma de suas funções a distribuição (e/ou reprodução) cultural e econômica. O currículo reflete um conjunto de escolhas feitas pelas instâncias governamentais a partir de um universo muito maior de conhecimentos e princípios sociais disponíveis, assim é uma forma de capital que reflete as "perspectivas e crenças de segmentos poderosos de nossa coletividade social" (Apple, 2006, p. 42).

Ainda, de acordo com esse autor, os conhecimentos (especialmente o aberto, pertencente ao currículo) encontrados nos ambientes de ensino e os princípios de seleção, organização e avaliação desses conhecimentos são governados pelo seu valor (social e/ou econômico) e oriundos de um universo muito mais amplo de conhecimento e de princípios de seleção possíveis. Portanto, não devem ser aceitos como dados, mas devem ser problematizados de maneira que as ideologias (sociais e/ou econômicas) e os significados padronizados institucionalmente que estão por trás deles possam ser examinados com cuidado (Apple, 2006).

Sacristán (1998) argumenta que o currículo prescrito é a cristalização/corporificação dos conteúdos e das práticas a serem utilizadas no desenvolvimento desses conteúdos nos sistemas educativos, sendo que a seleção e a organização dos entes que compõem o currículo prescrito é feita a partir das regulações inexoráveis - sociais, culturais, econômicas, políticas e administrativas - às quais estão submetidos os sistemas educativos. Além disso, "O currículo prescrito para o sistema educativo e para os professores, mais evidente no ensino obrigatório, é a sua própria definição, de seus conteúdos e demais orientações relativas aos códigos que o organizam, que obedecem às determinações que procedem do fato de ser um objeto regulado por instâncias políticas e administrativas" (Sacristán, 1998, p. 109). Nesse mesmo contexto, Saviani (2003, p. 43) discorre que o currículo "liga-se às ideias de: controle do processo pedagógico; estabelecimento de prioridades segundo as finalidades da educação, de acordo com o público a que se destina e com os interesses dos atores em disputa; ordenação, sequenciação e dosagem dos conteúdos de ensino".

\section{O conhecimento matemático do professor de Matemática}

A reflexão sobre a dimensão matemática da formação do professor de Matemática nos remete à teorização proposta por Lee Shulman, por ser ela uma das primeiras, mais influentes e citadas teorias, em nível internacional, que versam sobre os conhecimentos fundamentais à formação de professores. Shulman, em trabalhos publicados em 1986 e 1987, com especial ênfase no conteúdo, apresenta uma categorização dos conhecimentos considerados por ele como essenciais para o exercício da atividade docente e que intitulou de knowledge base. Dos Zetetiké, Campinas, SP, v.26, n.2, mai./ago., 2018, p.260-281

ISSN 2176-1744 
estudos de Shulman derivaram, pelo menos, cinco teorias voltadas exclusivamente ao conhecimento profissional do professor de Matemática, que são apresentadas a seguir.

Bromme (1993) apresenta uma decomposição analítica do conhecimento profissional dos professores de Matemática que se distingue da elaborada por Shulman especialmente pelo acréscimo do conceito de "fílosofia da matemática escolar" e pela distinção que estabelece entre os conceitos de "conhecimento da matemática escolar" e de "conhecimento da matemática como disciplina acadêmica" (Bromme, 1993). Assim, para este autor, o Conhecimento Profissional dos Professores de Matemática é composto pelo: a) conhecimento da Matemática como uma disciplina, b) conhecimento da Matemática escolar, c) conhecimento da filosofia da Matemática escolar, d) conhecimento sobre pedagogia geral (e psicologia), e) conhecimento pedagógico do conteúdo específico, isto é, da Matemática.

Deborah Ball e seus colaboradores, ao colocar ênfase no conhecimento do conteúdo específico e em seu uso para o ensino, estudaram o trabalho implicado no processo de ensinar e elaboraram o modelo analítico Mathematical Knowledge for teaching (MKT), em que elencam dois grandes grupos de conhecimentos presentes no ensino da Matemática: Subject Matter Knowledge e o Pedagogical Content Knowledge. A categoria Subject Matter Knowledge, por sua vez, subdivide-se em: Common Content Knowledge, Specialized Content Knowledge e Horizon Content Knowledge. Por outro lado, a categoria Pedagogical Content Knowledge subdivide-se em: Knowledge of Content and Students, Knowledge of Content and Teaching e Knowledge of Content and Curriculum (Ball, Thames \& Phelps, 2008; Hill, Ball \& Schilling, 2008).

Baumert e seus colaboradores, ao tomarem por base a conceitualização de conhecimento pedagógico do conteúdo elaborada por Shulman (1986), identificaram três subdimensões que são especialmente importantes para o ensino da Matemática: (1) Tasks play a central role in teaching mathematics; (2) Teachers need to work with students' existing conceptions and prior knowledge; (3) Students' construction of knowledge is often only successful with instructional support and guidance (Krauss, Baumert \& Blum, 2008, p. 875-876). De acordo com essa teoria, o Content Knowledge está posicionado entre a Matemática em nível escolar e a Matemática em nível universitário, domínio este que se refere a uma compreensão matemática profunda do conteúdo curricular a ser ensinado na escola. Esse aprofundamento, no entanto, se diferencia da pesquisa acadêmica em Matemática gerada em instituições de pesquisa e do conhecimento cotidiano matemático que os adultos retêm após deixarem a escola (Baumert et al., 2010).

José Carrillo e seus colaboradores, a partir das teorizações propostas por Shulman (1986, 1987) e Ball e colaboradores (Ball et al., 2008; Hill et al., 2008), apresentam um modelo analítico denominado Mathematics Teacher's Specialised Knowledge (MTSK), composto por dois subdomínios: Mathematical Knowledge e Pedagogical Content Knowledge. O Mathematical Knowledge subdivide-se em: Knowlegde of Topics; Knowlegde of the Structure of Mathematics; e Knowlegde of the Practice of Mathematics. O Pedagogical Content Knowledge, por sua vez, subdivide-se em: Knowledge of Mathematics Teaching; 
Knowledge of Features of Learning Mathematics; e Knowledge of Mathematics Learning Standards (Carrillo, Contreras \& Flores, 2013).

A teorização proposta por Liping Ma (2009), embora não se aproprie diretamente da categorização proposta por Shulman, foi elaborada sob a orientação deste autor. O cerne da teoria é o conceito de "Compreensão Profunda da Matemática Fundamental”, mediante o qual ela enfatiza os aspectos do conhecimento que contribuiriam mais decisivamente para o professor ser capaz de explorar e explicar ideias importantes da Matemática para os alunos. De acordo com Ma (2009), o termo fundamental possui três significados: a) elementar, por alocar-se no início da aprendizagem matemática; b) primário, por conter os rudimentos de conceitos matemáticos mais avançados e c) básico, por providenciar uma base para a futura aprendizagem matemática dos alunos. Além disso, de acordo com Ma, um entendimento profundo da Matemática tem "alcance" - capacidade de relacionar um tópico com tópicos de poder conceitual similar ou menor -, "profundidade" - capacidade de relacionar um tópico com aqueles de maior poder conceitual - e "abrangência" - capacidade de relacionar todos os tópicos (Ma, 2009, p. 215).

A partir das supramencionadas teorias, destacamos os seguintes aspectos sobre o conhecimento matemático do professor que ensina Matemática na escola: a) o conhecimento matemático se configura como uma das dimensões do conhecimento do professor de Matemática. Apesar de os autores se voltarem para o estudo da dimensão matemática do conhecimento do professor de Matemática, em nenhum momento eles negam a existência ou inferiorizam qualquer uma das demais dimensões do "conhecimento profissional do professor”, principalmente as dimensões didático-pedagógicas; b) a dimensão matemática do conhecimento do professor de Matemática se configura como uma composição entre o conhecimento pedagógico do conteúdo e o conhecimento do conteúdo. Ou seja, o professor de Matemática mobiliza, no decorrer de sua atividade profissional, tanto o conhecimento do conteúdo específico quanto o conhecimento pedagógico do conteúdo, de modo que a qualidade do ensino da Matemática está associada à mobilização, dentre outras, de ambos os conhecimentos, indissociáveis na prática docente; c) a diferenciação entre a Matemática como objeto do trabalho do professor de Matemática na Escola Básica e a Matemática como objeto de trabalho dos matemáticos.

Além disso, a literatura, ora apresentada, é unânime em apontar a incipiência de um constructo teórico fundamentado apenas na matemática acadêmica ou que represente "toda" Matemática necessária para o ensino de Matemática na escola em nível básico. Contudo, tendo em vista que esses modelos analíticos foram construídos a partir de pesquisas que têm como foco de estudo a atividade dos professores de Matemática em sala de aula, especialmente o modelo da Ball (precursor e influente), eles apresentam indicadores consistentes das características do conhecimento matemático do professor de Matemática da escola em nível básico, que são compostos pelas dimensões: Subject Matter Knowledge e Pedagogical Content Knowledge. 


\section{Uma análise do currículo do PROFMAT e seus principais resultados}

Conforme já mencionamos, o Projeto acadêmico do PROFMAT traz informações gerais do programa, contudo, para efeito deste artigo, focaremos na caracterização e análise do programa do Curso (objetivos, metas e diretrizes), na descrição das Disciplinas (grade e ementário), nas áreas de concentração/linhas de pesquisa e no perfil do corpo docente permanente.

No que concerne aos objetivos, metas e diretrizes do PROFMAT, de acordo com o projeto, o programa visa "atender professores de Matemática em exercício no ensino básico, especialmente na escola pública, que busquem aprimoramento em sua formação docente com ênfase no domínio aprofundado de conteúdo matemático relevante ao ensino básico" (SBM, 2010, p. 6). Pretende contribuir para

Uma qualificação ampla do ensino de matemática na escola básica, indo desde um aprimoramento no processo de formação continuada de professores até mudanças efetivas da prática em sala de aula. Esta ação visa promover a construção de competências matemáticas no ensino básico por meio de um processo de ensino e aprendizado significativo, inserido de forma consistente em uma educação universal de qualidade (SBM, 2010, p. 9).

Uma vez que

A meta é oferecer um curso de formação profissional alicerçado em sólida formação em Matemática, que contemple as necessidades advindas tanto do trabalho cotidiano dos professores no espaço da escola quanto de suas necessidades amplas de desenvolvimento e valorização profissional e que venha a fortalecê-los no enfrentamento dos desafios postos pelo seu exercício profissional (SBM, 2010, p. 9).

Assim sendo, esse Curso procurará contemplar:

a) a busca de uma formação matemática adequada para o exercício profissional qualificado do ensino de matemática na escola básica; b) a afirmação do compromisso permanente com a qualidade do ensino e da aprendizagem na área de Matemática; c) uma postura crítica acerca do trabalho nas aulas de matemática nos níveis fundamental e médio; d) o papel central da competência matemática frente às exigências da sociedade moderna; e) a valorização profissional do professor através do aprimoramento de sua formação (SBM, 2010, p. 9).

Para atingir os objetivos propostos no projeto, a prática nesse Mestrado Profissional em Matemática estará alicerçada nas seguintes diretrizes:

a) executar um processo de formação complementar em matemática, baseado nos conteúdos curriculares do ensino básico, que promova o domínio dos conteúdos apropriados, da forma de pensar e das estratégias de resolução de problemas característicos da matemática; b) promover uma articulação eficaz entre conhecimentos e práticas das ciências matemáticas e do ensino básico, direcionada aos objetivos da educação básica; c) estimular e promover a independência do professor cursista, fornecendo-lhe instrumentos para busca por conhecimento e desenvolvimento profissional de forma autônoma e permanente; d) incentivar a pesquisa e produção de materiais e práticas pedagógicas diferenciadas para 0 enriquecimento do processo de ensino e aprendizagem de Matemática na escola 
(textos, atividades, software, simulações, ambientes de aprendizagem, aulas inovadoras, etc.) (SBM, 2010, p. 9).

Conforme se observa, tanto os objetivos quanto as diretrizes e metas do PROFMAT reproduzem uma linguagem do interesse público geral e evidencia estar alinhado ao discurso comum sobre o papel social da educação e da formação de professores, em especial quando afirmam que o curso irá promover uma "qualificação ampla do ensino de matemática na escola básica" e que possui o "compromisso permanente com a qualidade do ensino e da aprendizagem na área de Matemática". Tal apropriação discursiva aproxima-se da classificação feita por Bowe, Ball e Gold (1992) dos documentos originários do contexto da produção de texto, à medida que adotam termos-chave que permeiam frequentemente o discurso político como, por exemplo, "qualidade do ensino", "exigências da sociedade", "qualificação" do ensino na "escola básica". Essas apropriações, de acordo com Bowe, Ball e Gold (1992), é que fazem um documento ser um representante da política.

O texto dos objetivos, diretrizes e metas do PROFMAT também se apropria frequentemente de expressões relacionadas a uma formação matemática sólida/ aprofundada/adequada para o exercício da docência, sendo que esse discurso é amplamente difundido e corroborado por diversos instrumentos vinculados ao referido programa. Contudo, em momento algum a proposta explicita e discute o significado de termos como "sólida formação em matemática", "formação matemática adequada para o exercício profissional qualificado do ensino de matemática na escola básica" e "domínio aprofundado da matemática". Essa discussão é fundamental tendo em vista tratar-se de um processo de formação continuada, em nível de pós- graduação stricto sensu, de professores que atuam na educação básica. Ou seja, o projeto acadêmico do PROFMAT não deixa claro, por exemplo, em que sentido dar-se-á este aprofundamento da Matemática. Seria no sentido de expandir a Matemática escolar na perspectiva da Matemática Acadêmica, tornando a primeira imagem e semelhança da segunda? Ou seria no sentido de aprofundar a matemática escolar dentro dela mesma, explorando seus fundamentos epistemológicos e buscando responder aos "porquês" conceituais e procedimentais, conforme é apontado por Bromme (1993), Ball (Ball et al., 2008; Hill et al., 2008), Baumert (Krauss et al., 2008; Baumert et al., 2010), Carrillo (Carrillo et al., 2013) e Ma (Ma, 2009)? Do ponto de vista curricular, essa falta de clareza é altamente problemática, porque pensar a matemática como conhecimento escolar é pensá-la como um "conhecimento sujeito a condicionantes sociais próprios da esfera escolar" (Lopes, 2007, p. 195), que são diferentes dos condicionantes que permeiam, por exemplo, as universidades e centros de pesquisa ao desenvolverem a matemática acadêmica (Ball et al., 2008), que é objeto de trabalho do "matemático profissional" (Moreira \& David, 2010; Fiorentini \& Oliveira, 2013).

Além disso, levando-se em conta que o PROFMAT é voltado unicamente à dimensão matemática da formação do professor dessa área do conhecimento na educação básica e considerando os objetivos, metas e diretrizes desse curso, especialmente ao enfatizarem que será desenvolvida uma formação continuada que fornecerá a "matemática adequada para o exercício profissional qualificado do ensino da matemática na escola básica" (SBM, 2010, p. 
09), o seguinte questionamento torna-se fundamental: Qual foi a matemática vista por esses professores na formação inicial (Licenciatura em Matemática) que não os capacitou adequadamente para o exercício profissional qualificado do ensino da matemática na educação básica, uma vez que é necessário cursarem mestrado profissional para obterem essa capacitação? Por outro lado, se o problema é a formação inicial do professor de matemática, não seria mais adequado investir na causa desse problema ou invés de tentar remediar seus efeitos? Ou seja, não seria mais lógico e pertinente investir na formação e desenvolvimento profissional dos formadores de professores que lecionam matemática na licenciatura do que nos professores já formados? Afinal os formadores de professores que atuam do PROFMAT não são os mesmos que atuam na formação inicial dos professores de matemática? Estes formadores teriam condições e conhecimentos profissionais da prática escolar para promover uma prática formativa em matemática diferenciada daquela que desenvolvem na formação inicial?

No que se refere às linhas de pesquisa e suas correspondentes áreas de concentração, o projeto acadêmico do PROFMAT apresenta o seguinte quadro:

Quadro 1: Áreas de concentração e Linhas de Pesquisa do PROFMAT

\begin{tabular}{|l|l|}
\hline \multicolumn{1}{|c|}{ Áreas de Concentração } & \multicolumn{1}{c|}{ Linhas de Pesquisa vinculadas } \\
\hline Álgebra & Teoria dos Números e Geometria Algébrica \\
\hline Análise Matemática & Análise Funcional e Equações Diferenciais Parciais \\
\hline Geometria e Topologia & Geometria Diferencial e Sistemas Dinâmicos \\
\hline Ensino de Matemática & Ensino Básico de Matemática e Ensino Universitário de Matemática \\
\hline Matemática Aplicada & Otimização e Análise Numérica \\
\hline
\end{tabular}

Fonte: SBM (2010)

A discussão sobre o significado dessas componentes de um Projeto Acadêmico de um programa de Pós-Graduação suscita seu entendimento pela CAPES. Assim, de acordo com essa fundação, as Áreas de Concentração expressam "a vocação inicial e/ou histórica do Programa". Neste sentido, elas devem "indicar, de maneira clara, a área do conhecimento à qual pertence o programa, os contornos gerais de sua especialidade na produção do conhecimento e na formação esperada", enquanto as Linhas de Pesquisas "expressam a especificidade de produção de conhecimento dentro de uma área de concentração e são sustentadas, fundamentalmente, por docentes/pesquisadores do corpo permanente do programa". (CAPES, 2010, p. 21). Já a área do conhecimento "corresponde ao domínio ou campo geral do conhecimento a que se referem as atividades do Programa. Cada programa vincula-se a uma área básica, que deve constar da Tabela de Áreas do Conhecimento utilizada pela Capes. (CAPES, 2010, p. 12). 
Assim, ao estabelecermos um paralelo entre essas áreas de concentração presentes no currículo do PROFMAT e a tabela das áreas do conhecimento da CAPES ${ }^{5}$, constatamos que, com exceção da área "Ensino de Matemática", todas as demais figuram na área de avaliação "Matemática/Probabilidade e Estatística". Tal constatação faz emergir algumas considerações. A primeira delas relaciona-se à coerência da classificação do PROFMAT como pertencente à área de avaliação Matemática, uma vez que, quase em sua totalidade, as áreas de concentração do PROFMAT figuram nessa área do conhecimento. A segunda consideração diz respeito às características dos conhecimentos que serão produzidos por esse programa, que, de acordo com essa classificação, será quase que em sua totalidade de natureza matemática. Sendo que essa matemática está vinculada à prática do matemático profissional e não à prática do professor que ensina essa área do conhecimento na educação básica (Ball et al., 2008; Fiorentini \& Oliveira, 2013; Losano \& Fiorentini, 2018), uma vez que o conhecimento escolar difere do conhecimento dos centros de pesquisa e de outros saberes sociais (Lopes, 2007).

Desse modo, de uma perspectiva de disseminação cultural (Apple, 2006; Sacristán, 1998; Bowe, Ball \& Gold, 1992), tal política pública de formação de professores pode ser entendida como disseminadora, por meio de suas áreas de concentração e linhas de pesquisa, da cultura que permeia a prática do matemático profissional. Entretanto, tal processo de disseminação cultural distancia-se dos conhecimentos que o professor de matemática suscita ao ensinar esse conhecimento na educação básica, conforme destacam Bromme (1993), Ball (Ball et al., 2008; Hill et al., 2008), Carrillo (Carrillo et al., 2013) e Ma (Ma, 2009).

Retomando os dados discriminados no Projeto Acadêmico do PROFMAT, constatamos que é apresentada a seguinte relação de disciplinas obrigatórias: Números e Conjuntos; Matemática Discreta; Geometria I; Aritmética I; Resolução de Problemas; Equações Algébricas e Noções de Cálculo; Geometria II e Trabalho de Conclusão de Curso. No que se refere às disciplinas eletivas é apresentada a seguinte relação: Cálculo Diferencial e Integral: Um segundo curso; Aritmética II; Introdução à Álgebra Linear; História da Matemática; Recursos Computacionais no Ensino de Matemática; Matemática e Atualidade; Modelagem Matemática e Tópicos de Matemática.

A ementa da disciplina "Equações Algébricas e Noções de Cálculo" é composta pelos seguintes conteúdos: Números complexos; interpretação geométrica, forma trigonométrica e transformações conformes (semelhança e inversão no plano). Breve apresentação dos quatérnios. Polinômios; divisibilidade, equações algébricas; equações do terceiro e quarto graus, relações entre coeficientes e raízes, o Teorema Fundamental da Álgebra. Noção de derivada; cálculo das derivadas de funções elementares; regra da cadeia, Teorema do Valor Médio; uso da derivada para obter o gráfico de uma função: gráficos de polinômios e das funções exponenciais, logarítmicas e trigonométricas. Problemas de máximo e mínimo. tualizada_2017_v2.pdf, acesso em: 16/03/2018. 
Séries de Taylor das funções elementares; seu uso para estimativas simples. Noção de integral; Teorema Fundamental do Cálculo. Áreas e volumes obtidos mediante integrais. A análise de tais conteúdos, tendo como base os conhecimentos comumente veiculados pelos currículos de matemática utilizados na educação básica, evidencia que, com exceção de "Números complexos; interpretação geométrica, forma trigonométrica" e "Polinômios; divisibilidade, equações algébricas; equações do terceiro e quarto graus, relações entre coeficientes e raízes, o Teorema Fundamental da Álgebra", todos os demais conteúdos não são objeto direto do ensino da matemática em nível escolar.

Do mesmo modo, a análise do ementário das disciplinas de "Cálculo Diferencial e Integral: Um Segundo Curso" - composta pelos conteúdos: Derivadas parciais. Regra da cadeia. Gradiente e seu significado. Pontos críticos de uma função de n variáveis. Integral múltipla. Noção de equação diferencial. Equação diferencial linear com coeficientes constantes - e "Introdução à Álgebra Linear" - composta pelos conteúdos: Espaço vetorial. Dependência linear, base. Transformação linear; matriz de uma transformação linear. Operações com matrizes. Determinantes, Transformações ortogonais. Matrizes simétricas. Diagonalização - evidencia que os conteúdos abordados nelas não são objeto direto do ensino da matemática em nível escolar.

Por outro lado, os conteúdos presentes no ementário das disciplinas "Equações Algébricas e Noções de Cálculo" e "Cálculo Diferencial e Integral: Um segundo curso" são comumente abordados em cursos de Cálculo em nível universitário (de graduação em Matemática - licenciatura e bacharelado -, além de cursos do intitulado "ciclo básico" de cursos como Engenharia, Física, Química, Geologia, etc.), enquanto que os conteúdos pertencentes ao ementário da disciplina "Introdução à Álgebra Linear" geralmente figuram em cursos de Álgebra Linear em nível universitário.

A análise do ementário da disciplina "Aritmética I" evidencia que, com exceção dos conteúdos "Divisão. O algoritmo de Euclides. Máximo divisor comum e mínimo múltiplo comum. Números primos. Fatoração. Teorema Fundamental da Aritmética”, todos os demais - Equações diofantinas lineares. Congruências e aritmética módulo n. Números invertíveis módulo n. A função phi de Euler. O Teorema de Euler e o Pequeno Teorema de Fermat. Aplicações a Criptografia RSA. O Teorema Chinês dos Restos. - também não são objeto direto do ensino da matemática em nível escolar, uma vez que figuram em cursos da área de álgebra em nível de graduação e matemática (Licenciatura e Bacharelado).

Já em relação a disciplina “Aritmética II", a análise de seu ementário evidencia que os conteúdos contemplados por ela não figuram nem no currículo escolar nem nos currículos de cursos de graduação, uma vez que tais conhecimentos geralmente são objetos de estudos em programas de pós-graduação (mestrado acadêmico) em matemática. A saber, esses conteúdos são: Equações diofantinas de grau 2. Triplas pitagóricas. Ordens e raízes primitivas. Resíduos quadráticos. Reciprocidade quadrática. Funções multiplicativas e as fórmulas de inversão de Möbius. Frações contínuas e aproximações de números reais por números racionais. A equação de Pell. 
A ementa da disciplina "Geometria I" abarca, quase que em sua totalidade, conteúdos que são objeto direto da prática do professor de matemática da educação básica e também figuram no ementário dos cursos de Licenciatura em Matemática: Ângulos; bissetrizes, perpendiculares, ângulos retos. Retas paralelas; soma dos ângulos internos de um triângulo, casos de igualdade de triângulos. Paralelogramos, polígonos regulares. Círculo e circunferência, ângulos inscritos, tangentes. Semelhança de figuras planas. Áreas, Teorema de Pitágoras. Comprimento da circunferência, número $\pi$. Retas e planos no espaço. Volumes dos sólidos. Princípio de Cavalieri. Tais conteúdos também figuram no currículo de cursos em nível universitário (graduação). O mesmo ocorre com as disciplinas "Matemática Discreta" - cujo ementário é composto pelos seguintes conteúdos: Princípios básicos da Combinatória. O Teorema de Ramsey. Conceitos elementares de Probabilidade. Probabilidade condicional. Progressões aritméticas e geométricas. Sequências recorrentes. Noções sobre juros e descontos. Taxas equivalentes. Vários problemas de matemática financeira. - e "Números e Conjuntos" - cujo ementário contempla os conteúdos: Conjuntos. Números naturais. Números Cardinais. Números reais. Funções afins. Funções Quadráticas. Funções Polinomiais. Funções Exponenciais e Logarítmicas. Funções Trigonométricas.

Já na disciplina de "Geometria II" somente os conteúdos "Geometria Analítica Plana: coordenadas, equações da reta e das cônicas", "Coordenadas no espaço" e "Determinantes 3X3" presentes no ementário figuram no currículo escolar de matemática, uma vez que os demais conteúdos pertencentes à ementa - Vetores no plano. Equação do plano, interpretação geométrica dos sistemas lineares com três incógnitas. Cálculo vetorial no espaço; produto interno e produto vetorial. Volume do paralelepípedo. Quádricas; formas quadráticas e obtenção dos eixos principais - geralmente são abordados em disciplinas da área de Geometria Analítica de cursos em nível universitário (de graduação em Matemática licenciatura e bacharelado -, além de cursos do intitulado "ciclo básico" de cursos como Engenharia, Física, Química, Geologia, etc.).

A disciplina "História da Matemática" é apresentada por meio de uma sequência de conteúdos específicos da história da matemática como área de pesquisa e não como metodologia de ensino e sem projetar um uso pedagógico da história da matemática no ensino. Esses conteúdos são: Origem da ideia de número e a escrita primitiva dos mesmos; sistemas de numeração; A Geometria no Egito, na Babilônia e na Grécia; O nascimento do método dedutivo: Tales, Pitágoras e Euclides; A Matemática no Renascimento: as equações do terceiro e do quarto graus; Cardano, Tartaglia, Bombelli e o surgimento da Álgebra; Descartes e Fermat: uma Matemática nova; Newton, Leibniz e o Cálculo; Estudo das raízes históricas dos conceitos básicos: equação do segundo grau na Babilônia, trigonometria na Grécia, números complexos com Bombelli e depois com Gauss, a Geometria dos Elementos; Os logaritmos com Neper e Briggs; As cônicas com Apolônio; Números complexos com Gauss, Euler e Cauchy; Cálculo com Newton. Além disso, boa parte dos temas veiculados pela ementa é objeto de estudo da matemática em nível universitário. 
No que concerne à disciplina "Recursos Computacionais no Ensino de Matemática", sua ementa evidencia a existência de uma associação entre seus conteúdos e uma das demandas emergentes da prática do professor de matemática que atua na educação básica, o ensino de matemática a partir do uso de recursos computacionais, uma vez que pretende: apresentar e discutir programas computacionais para o ensino de matemática em ambientes de sala de aula e de laboratório didático; Softwares livres; a discutir o planejamento de aulas nas escolas fundamental e média em ambiente informatizado e uso de calculadoras no ensino de matemática; a abordar a pesquisa eletrônica, a coleta e a disponibilização de material didático na rede, os processadores de texto e hipertexto, as planilhas eletrônicas, os pacotes estatísticos, o banco de dados, além de abordar ambientes gráficos, ambientes de geometria dinâmica, sistemas de computação simbólica, critérios e instrumentos para avaliação de softwares educativos e o ensino a distância, em modalidades síncrona e assíncrona (SBM, 2010).

As disciplinas eletivas (não obrigatórias) "Matemática e Atualidade" (composta pelos seguintes conteúdos: Matemática e música. Sons. Compactação de arquivos de sons. Senhas usadas em bancos e na Internet. Códigos. A Geometria do globo terrestre. Funcionamento do GPS. A matemática dos códigos de barra. Aplicações de cônicas. Os logaritmos, escalas. Outros temas vinculados a inovações tecnológicas), "Modelagem Matemática" (composta pelos conteúdos: A filosofia científica da modelagem matemática de problemas do mundo real. A modelagem matemática na sala de aula e seus principais desafios. Exploração das principais etapas da modelagem de problemas que utilizam ferramentas matemáticas do Ensino Médio. Observação de problemas reais, identificação das componentes variáveis e dos parâmetros importantes inerentes ao modelo e as suas interações. Estratégias de modelagem e construção de modelos matemáticos de problemas reais: Hipóteses para o modelo. Formulação e resolução matemática do problema. Interpretação da solução. Validação do modelo. Uso do modelo para explicar e prever os fenômenos associados ao modelo. Aperfeiçoamento de modelos. Coleta de dados e estimativa dos parâmetros a serem usados no modelo. Ferramentas matemáticas e estatísticas para tratamento de dados. Variações simples, média e relativa. Ajustes. Modelos discretos. Equações discretas. Solução teórica, gráfica e numérica de equações discretas.) e "Resolução de Problemas" (composta pelos conteúdos: Estratégias para resolução de problemas. Problemas de Combinatória. Problemas de Teoria dos Números. Problemas envolvendo desigualdades. Problemas envolvendo Indução. Problemas envolvendo sequências. Problemas envolvendo polinômios. Problemas envolvendo equações funcionais. Problemas de Geometria. Problemas de Cálculo. Problemas envolvendo jogos. Análise de exames e testes: PISA, SAEB, ENEM e afins. Estudo de provas de olimpíadas: OBM, OBMEP, Olimpíada do Cone Sul, Olimpíada Internacional de Matemática, Olimpíada Iberoamericana de Matemática, Concurso Canguru sem fronteiras.) abarcam, em sua maioria, temas que, a princípio, são pertinentes à prática do professor da educação básica. Entretanto, apenas a primeira delas não costuma figurar na grade dos cursos de Licenciatura em Matemática. Cabe, por outro lado, destacar que, embora essas disciplinas sejam relevantes à formação 
matemática do professor, podem não ser oferecidas aos mestrandos, pois são disciplinas eletivas, isto é, não obrigatórias do curso.

A disciplina "Tópicos de Matemática" não possui "ementa fixa", uma vez que o programa poderá "ser proposto por iniciativa individual das Instituições Parceiras" do PROFMAT (SBM, 2010).

Nessa conjuntura temos o seguinte cenário: a maioria dos conhecimentos veiculados pelas disciplinas constantes na grade do PROFMAT - e principalmente a abordagem dada a eles, por meio das bibliografias constantes no projeto acadêmico - foram, em princípio, trabalhados nas licenciaturas. Não há indícios, nem orientações, de que essa replicação seja diferenciada da graduação, tendo em vista tratar-se de um contexto de formação continuada de professores. Esse fato coloca em evidência uma contradição: se esse currículo privilegiado na Licenciatura em Matemática ${ }^{6}$ não proporcionou a formação matemática adequada e necessária para a prática do professor de Matemática, por que o repetir na formação continuada? Nesse sentido, concordamos com o questionamento feito por Moreira e David (2010) de que a replicação de uma formação matemática inócua na Licenciatura em Matemática também tende a ser inócua no PROFMAT, pois os conhecimentos matemáticos privilegiados não contemplam os conteúdos matemáticos considerados pela literatura atual como sendo relevantes e fundamentais para a prática do docente de matemática no ambiente escolar.

A discussão em torno dos conhecimentos considerados como "legítimos" (Apple, 2006) pelo PROFMAT e pelas instâncias governamentais que o aprovaram e financiam, uma vez que foram inseridos em seu currículo (Bowe, Ball \& Gold, 1992), evidenciam as características dos conhecimentos que decisores políticos julgam importantes e necessários os professores de matemática saberem (Ball, Lubienski \& Mewborn, 2001). A literatura atual (Shulman, 1986 e 1987; Bromme,1993; Ball et al., 2008; Hill et al., 2008; Krauss et al., 2008; Baumert et al, 2010; Carrillo et al., 2013; Ma, 2009; Moreira \& David, 2010; e Fiorentini \& Oliveira, 2013), por outro lado, aponta que os conhecimentos considerados essenciais e relevantes para a prática do professor de matemática não se reduzem à imagem e semelhança da matemática acadêmica, principalmente em relação aos seus processos sintáticos e procedimentais de formalização e sistematização. Isso porque o rigor matemático, por enfatizar a sintaxe em detrimento da semântica e das epistemologias deste conhecimento, pode impedir que o professor (ou futuro professor) tenha acesso aos significados essenciais e fundamentais da matemática enquanto campo de conhecimento e prática social em diferentes contextos, sendo o contexto acadêmico apenas um destes. Ball et al. (2008), por exemplo, diferenciam o "conhecimento comum" de matemática - que todo o cidadão deveria saber do "conhecimento especializado do conteúdo" para ensinar - que todos os professores de matemática deveriam saber para ensinar e que se diferencia do conhecimento matemático acadêmico ou de outras profissões - e do "conhecimento matemático em horizonte" -

\footnotetext{
${ }^{6}$ Conforme determinam as "Diretrizes Curriculares Nacionais para os Cursos de Matemática, Bacharelado e Licenciatura" (CNE, 2001).
} 
conhecimento extensivo da matemática, isto é, de outros tópicos do currículo escolar da matemática ou do campo do conhecimento matemático e que têm conexão ou relação com o que se ensina e aprende na escola.

Além disso, o conhecimento matemático que o professor precisa saber para ensinar matemática, de acordo com Fiorentini e Oliveira (2013),

não é o mesmo que requer o bacharel para ser um matemático bem sucedido. Não estamos, com essa afirmação, querendo defender uma matemática mais simples ou superficial para o professor. Ao contrário, defendemos que o professor de matemática precisa conhecer, com profundidade e diversidade, a matemática enquanto prática social e que diz respeito não apenas ao campo científico, mas, sobretudo, à matemática escolar e às múltiplas matemáticas presentes e mobilizadas/produzidas nas diferentes práticas cotidianas. O domínio desses conhecimentos certamente proporcionará condições para o professor explorar e desenvolver, em aula, uma matemática relevante, isto é, uma matemática que faça sentido aos alunos, ao seu desenvolvimento intelectual, sendo capaz de estabelecer interlocução/conexão entre a matemática mobilizada/produzida pelos alunos e aquela historicamente produzida pela humanidade (p. 924).

Os autores da literatura atual, além de questionarem o tipo de conhecimento matemático que interessa à formação e ao trabalho do professor, destacam outros relacionados às dimensões didático-pedagógicas, curriculares, epistemológicas, antropológicas, linguísticas e psicológicas relativas ao ensino e à aprendizagem da Matemática para as crianças, jovens e adultos que frequentam a escola em diferentes contextos. De fato, o professor de Matemática mobiliza, no decorrer de sua atividade profissional, tanto o conhecimento do conteúdo específico ou especializado para ensinar matemática, como destacam Ball et al (2008) e Carrilllo et al. (2013), quanto o conhecimento pedagógico do conteúdo, o conhecimento curricular e seus respectivos materiais didáticos e paradidáticos, além do conhecimento pedagógico (geral), do conhecimento de contextos educacionais e do conhecimento sobre as características dos processos de ensino e de aprendizagem. Por isso a qualidade do ensino da Matemática está associada à mobilização dos diversos conhecimentos que compõem a formação profissional do professor de matemática, uma vez que estes são indissociáveis no exercício da prática docente.

Neste contexto, isto é, considerando que a matemática privilegiada pelo PROFMAT é de natureza diferente da matemática da escolar, resta, como possibilidade para o mestrando profissional desenvolver e problematizar o que tem aprendido no curso em relação à sua prática profissional: o "Trabalho de Conclusão de Curso" (TCC). De acordo com o projeto acadêmico do PROFMAT, o TCC está instituído na grade curricular como uma disciplina obrigatória, composta pelos seguintes conteúdos:

Cada aluno matriculado na disciplina Trabalho de Conclusão do Curso receberá um tema específico pertinente ao currículo acima para desenvolver em um projeto escrito sob orientação docente. Este projeto incluirá um apanhado histórico sobre o tema, uma análise crítica sobre as fontes disponíveis para o tema, um planejamento de aula, desenvolvimento didático do tema e um conjunto de exercícios resolvidos, que ilustre o processo de aprendizado e domínio do tema. O trabalho de conclusão será 
apresentado na forma de uma aula expositiva sobre o tema do projeto e de um trabalho escrito, com a opção de apresentação produção técnica relativa ao tema. A nota final é baseada no conjunto apresentado (SBM, 2010, p. 83).

Conforme evidencia esta orientação, o TCC a ser produzido, de acordo com o projeto acadêmico do PROFMAT, deveria abordar temas pertinentes às disciplinas obrigatórias do próprio programa de pós-graduação, o que não garante que esses temas sejam originários e derivados da prática do professor ao ensinar matemática na educação básica ou aplicáveis em sala de aula. Tal fragmento determina, também, a estruturação do projeto que deveria dar origem ao TCC, devendo este ser composto por um "apanhado histórico sobre o tema, uma análise crítica sobre as fontes disponíveis para o tema, um planejamento de aula, desenvolvimento didático do tema e um conjunto de exercícios resolvidos, que ilustre o processo de aprendizado e domínio do tema" (SBM, 2010, p. 83). Conforme se observa, em nenhum momento as prescrições que versam sobre o TCC o vinculam à educação básica, seja por meio da implementação desse projeto no ambiente escolar, ou pela análise e discussão de materiais didáticos pertencentes ou pertinentes à prática do docente de matemática nesse nível educacional (como livros didáticos e paradidáticos, currículo escolar, etc.).

Conforme teorização desenvolvida por Sacristán, cabe ao currículo prescrito difundir "os códigos sobre o que deve ser a cultura nas instituições de ensino, tornando-os públicos" (Sacristán, 2013, p. 27). Nesse sentido, questionamos por que o PROFMAT difunde e trabalha, junto aos seus estudantes, muito mais a Matemática de natureza acadêmica e técnico-formal do que a Matemática cuja natureza está associada à prática do profissional do professor?

Por último, em relação à caracterização do corpo docente apresentado no projeto acadêmico do PROFMAT (área de formação e produção acadêmica), constata-se que, dos 53 docentes citados, 45 possuem o título de doutorado na área de Matemática. Dos oito que não possuem doutorado em matemática, quatro possuem o título de doutor em "Engenharia de Sistemas e Computação", um em "Operations Research", um em "Engenharia da Produção", um em "Engenharia Elétrica" e um em "Educação Matemática". A formação desses docentes corrobora nossa afirmação anterior sobre a coerência da classificação do PROFMAT como pertencente à área de avaliação Matemática, uma vez que é a formação e atuação desses profissionais que dá sustentação à produção de conhecimento dentro de uma área de concentração (CAPES, 2010). Assim, à medida que o PROFMAT foi avaliado e considerado, dentro dos critérios estabelecidos pela CAPES, como pertencente a área de Matemática é porque a produção acadêmica desses pesquisadores pertence a essa área. Dessa forma, de uma perspectiva de disseminação do cultural, o PROFMAT e as instâncias políticas governamentais privilegiam, conforme Apple (2006), Sacristán (1998) e Bowe, Ball \& Gold (1992), os conhecimentos produzidos pela comunidade acadêmica de matemática, pressupondo que a prática de qualidade do professor de matemática pauta-se unicamente em conhecimentos dessa natureza. 


\section{Conclusões e Consideraçãa finais}

A análise do currículo oficial do PROFMAT evidencia que esse documento, que representa e baliza o curso, apropria-se de uma linguagem de interesse público comum, empregando em seu discurso expressões genéricas como "qualidade do ensino", "exigências da sociedade" e "qualificação" do ensino na "escola básica", ao propor um programa de formação para professores que ensinam matemática na educação básica (anos finais do Ensino Fundamental e Ensino Médio). A estruturação desse processo formativo - por meio das áreas de concentração (e respectivas linhas de pesquisa), grade do curso (ementário e bibliografias das disciplinas) e corpo docente permanente - se pauta na disseminação das práticas e códigos característicos da prática do matemático profissional. Portanto, pode-se concluir que esse curso, visa disseminar a cultura e a ideologia características da comunidade acadêmica de matemática.

Além disso, o conhecimento valorizado pelas instâncias governamentais que financiam o PROFMAT, consequentemente considerados por elas como necessário e suficiente, para o ensino qualificado da matemática na educação básica relaciona-se fortemente aos conhecimentos acadêmicos vinculados à realização de pesquisas na área da matemática e em cursos em nível de graduação.

Nesse cenário, os estudantes (professores da educação básica) que frequentam o PROFMAT tendem a ser vistos como tábulas rasas em termos de conhecimentos profissionais, devendo, nessa perspectiva, se apropriar da matemática acadêmica para posteriormente aplicá-la na prática escolar. Ou seja, a proposta curricular do PROFMAT parece repetir o mesmo movimento que critica - relativa à formação deficitária do professor por parte das Licenciaturas em Matemática - para justificar sua implementação e reconhecimento como política pública. E a solução que propõem para remediar esse problema, como vimos na análise desse documento, parece ser a mesma, pois todas as disciplinas obrigatórias do curso são aquelas previstas pelas Diretrizes Curriculares para Cursos de Graduação em Matemática (CNE, 2001). Por ser o mestrado profissional um processo de formação continuada (ou em serviço) de professores que têm, em sua maioria, estudantes com grande experiência de docência em matemática, não deveria o curso tomar como ponto de partida ou pelo menos como campo de estudo e problematização as práticas e os saberes experienciais que os professores construíram ao longo da carreira? Entendemos que uma formação docente dissociada das práticas profissionais de ensinar e aprender matemática na escola até pode fazer sentido na formação inicial de futuros professores, mas não em um contexto de formação continuada de professores em serviço.

Ademais, a literatura atual no campo da formação de professores de matemática, como mostramos ao longo do artigo, é enfática ao mostrar que os preceitos da matemática acadêmica pouco contribuem para um efetivo desenvolvimento profissional do professor de matemática em termos de conhecimento matemático. Não queremos com isso desqualificar a matemática acadêmica. Ao contrário, queremos resgatar sua potencialidade formativa, mas 
sob outra perspectiva. Isto é, como mediação importante, conforme destacam Losano e Fiorentini (2018), tendo como ponto de partida e de chegada, em um contexto de formação continuada ou de formação profissional em serviço, as práticas e os saberes experienciais que os professores têm produzido e trazem para a formação em um mestrado profissional. Esse empreendimento, entretanto, demanda uma ação colaborativa entre pesquisadores e formadores vinculados tanto à formação matemática do professor como à formação didáticopedagógica de um conhecimento especializado para ensinar matemática nas escolas, conforme destacam Ball et al (2008), Fiorentini e Oliveira (2013) e Carrillo et al. (2013).

Esse desafio e os resultados do presente estudo nos inspiram a propor políticas públicas que invistam na formação dos formadores de professores de matemática, pois são estes profissionais que podem efetivamente transformar e melhorar tanto a formação inicial como a continuada de professores matemática que atuam na educação básica, tendo como suporte e mediação a exploração e a investigação de conhecimentos profissionais fundamentais para uma prática qualificada de ensino e aprendizagem matemática nas escolas e nos cursos de licenciatura.

\section{Agradecimentos:}

Agradecemos o apoio financeiro do Conselho Nacional de Desenvolvimento Científico e Tecnológico (CNPq) para o desenvolvimento desta pesquisa.

Agradecemos também aos pareceristas ad hoc da revista Zetetiké pelas importantes contribuições que ajudaram a melhorar a qualidade deste artigo.

\section{Referências}

Apple, M. W. (2006). Ideologia e Currículo. Porto Alegre: Artmed.

Ball, D. L., Lubienski, S., and Mewborn, D. (2001). Research on teaching mathematics: The unsolved problem of teachers' mathematical knowledge. In V. Richardson (Ed.), Handbook of research on teaching (4th ed.) (pp. 433-456). New York: Macmillan.

Ball, D. L.,Thames, M. H. \& Phelps, G. (2008). Content knowledge for teaching: what makes it special? Journal of Teacher Education, 59(5), 389-407.

Ball, S.J. (2015). What is policy? 21 years later: reflections on the possibilities of policy research. Discourse, 36(3), 306-313.

Bowe, R.; Ball, S. \& Gold, A. (1992). Reforming education and changing schools: case studies in policy sociology. London: Routledge.

Baumert, J., Kunter, M., Blum, W., Brunner, M., Voss, T., Jordan, A., Klusmann, U., Krauss, S., Neubrand, M. \& Tsai, M. (2010) Teachers' mathematical knowledge, cognitive activation in the classroom, and student progress. American Educational Research Journal, 47(1), 133-180. 
Conselho Nacional de Educação (CNE). (2001). Parecer CNE/CES 1.302/2001. Diretrizes Curriculares para Cursos de Matemática, Licenciatura e Bacharelado. Brasília: Conselho Nacional de Educação.

Coordenação de Aperfeiçoamento de Pessoal de Nível Superior (CAPES). (2010). APCN 2010. Aplicativo para Propostas de Cursos Novos. CAPES: Brasília.

Coordenação de Aperfeiçoamento de Pessoal de Nível Superior (CAPES). (2013). Avaliação Suplementar Externa do Programa de Mestrado Profissional em Matemática em Rede Nacional (PROFMAT). Brasília.

Bromme, R. (1993). Beyond subject matter: a psychological topology of teachers' professional knowledge. In R. Biehler, R. Scholz, R. Sträßer \& B. Winkelmann (Eds.). Mathematics didactics as a scientific discipline. The state of the art (pp. 73-88). Dordrecht: Kluwer.

Carrillo, J., Contreras, L. C. \& Flores, P. (2013). Un modelo de conocimiento especializado del profesor de matemáticas. In L. Rico, M. C. Cañadas, J. Gutiérrez, M. Molina \& I. Segovia (Eds.) Investigación en Didáctica de la Matemática. Libro homenaje a Encarnación Castro (pp. 193-200). Granada: Comares.

Fiorentini, D. \& Oliveira, A. T. C. C. (2013) O Lugar das Matemáticas na Licenciatura em Matemática: que matemáticas e que práticas formativas? Bolema, 27(47), 917-938

Gatti, B. A., Barretto, E. S. S., \& André, M. E. D. A (2011). Políticas docentes no Brasil: um estado da arte. Brasília: Unesco.

Hill, H.C., Ball, D. L., \& Schilling, S. G. (2008). Unpacking "Pedagogical Content Knowledge”. Journal for Research in Mathematics Education, 39(4), 372-400.

Krauss, S., Baumert, J., \& Blum, W. (2008). Secondary mathematics teachers' pedagogical content knowledge and content knowledge: validation of the COACTIV constructs. Zentralblatt für Didaktik der Mathematik, 40(5) 873-892.

Lopes, A. C. (2007). Currículo e Epistemologia. Ijuí: Editora UNIJUÍ.

Losano, A. L., \& Fiorentini, D. (2018). Análise das ênfases formativas de mestrados profissionais destinados a professores de matemática. Revista Internacional de Educação Superior [RIESup], 4(2), 1-30 (AOP).

Ma, L. (2009). Saber e Ensinar Matemática Elementar. Lisboa: Gradiva.

Mainardes, J. (2006). Abordagem do ciclo de políticas: uma contribuição para a análise de políticas educacionais. Educação e Sociedade, 27(94), 47-69.

Moreira, P. C., \& David, M. M. (2010). A formação matemática do professor: licenciatura e prática docente. (Coleção Tendências). Belo Horizonte: Autêntica Editora.

Sacristán, J. G. (1998). O currículo: uma reflexão sobre a prática. Porto Alegre: ArtMed.

Sacristán, J. G., (2013). O que significa o currículo. In J., G. Sacristán (Ed.) Saberes e incertezas sobre o currículo (pp.16-38). Porto Alegre: Penso.

Saviani, N. (2003). Saber Escolar, Currículo e Didática: Problemas da unidade conteúdo/método no processo pedagógico (4a ed.). Campinas: Autores Associados. 
Shulman, L. S. (1986). Those who understand: Knowledge growth in teaching. Educational Researcher, 15(2), 4-14.

Shulman, L. S. (1987). Knowledge and teaching: foundations of the new reform. Harvard Educational Review, 57(1), 1-22.

Sociedade Brasileira de Matemática (SBM). (2010). Projeto Acadêmico do PROFMAT. Rio de Janeiro: SBM.

Sociedade Brasileira de Matemática (SBM). (2017). PROFMAT: uma reflexão e alguns resultados. Rio de Janeiro: SBM. 